\title{
Using Social Media to Connect College Students with Mental Health Services
}

\author{
Erica J Seidel ${ }^{1}$, Danna Ethan ${ }^{2}$ and Corey $\mathrm{H} \mathrm{Basch}^{3 *}$ \\ ${ }^{1}$ Department of Student Life, Borough of Manhattan Community College, The City University of New York, New York, New York, USA \\ ${ }^{2}$ Department of Health Sciences, Lehman College, The City University of New York, Bronx, New York, USA \\ ${ }^{3}$ Department of Public Health, William Patterson University, Wayne, New Jersey, USA
}

In recent years, the severity and incidence of mental health issues in college students has increased. A significant body of research suggests that college students are presenting with more psychological distress than ever. Compared to five years ago, $82 \%$ of respondents of the American College Counseling Association's 2013 National Survey of College Counseling Centers reported increases in the number of students with severe psychological problems [1]. The American College Health Association's National College Health Assessment (ACHANCHA) shows a considerable amount of psychological symptomology in the college population [2]. Over 123,000 students surveyed in spring 2013 report that at some point in the past 12 months, $31.3 \%$ felt so depressed that it was difficult to function and 51\% felt overwhelming anxiety. This level of depression and anxiety is a serious health concern for college communities.

Counseling centers are working hard to meet this need but many students in need of treatment do not seek help [3]. Just $11 \%$ of those in the ACHA-NCHA survey reported being treated or diagnosed by a professional for their depression and only $12.9 \%$ of students reported being diagnosed or treated by a professional for anxiety. Counseling center directors reported a small fraction of students being served by their counseling service in the 2012 Association for University and College Counseling Center Director's survey. Directors reported that the average percent of students seeking counseling services is $9-12 \%$ at small colleges and 6-7\% at larger colleges/universities. If just a small segment of college students utilize traditional counseling services while the severity and prevalence of mental health issues on campuses continue to increase, we must question how students' needs are being met and whether they are seeking help.

Students in distress may reach out to trusted adults that they see on a regular basis, such as their professors. These educators often want to assist students but generally are not trained or licensed to provide the needed level of counseling [4]. Understanding that not everyone who needs professional help knows how to obtain it or feels comfortable doing so, college mental health is moving toward the idea that the entire campus should be a safety net where students can access support and appropriate referrals in a variety of ways through multiple points of access [5]. An access point as rich as the Internet is a natural next step.

Social media has become more prominent and integrated into our lives over the past decade. This is especially true for college students, with $83 \%$ of those ages 18 to 29 using social media [6]. Individuals are already favorably connected to social media sights as $85 \%$ of adults using social networking sites feel their experiences are mostly kind and overall positive [7]. While college students in need of psychological services don't always reach out to the counseling center, we do know that many are expressing their emotions in some way, via social media. A recent examination of Facebook status updates of 200 college students revealed that $25 \%$ expressed symptoms consistent with depression [8].

Given the high percentage of students using social media, it seems time for college mental health professionals to catch up and become part of their virtual world. Facebook and Twitter are perhaps among the most known social media outlets but there are numerous other platforms that can be inhabited by counselors. Forums, websites, and picture-sharing apps like Instagram are all potential new ground for counselors. Gone are the days of waiting for students to knock on counselors' doors and present with some kind of emotional distress. They are expressing this distress in new ways, sometimes to professors and sometimes online to friends or strangers.

Today's social media goes beyond a simple Facebook page with information and links. It allows counselors the ability to interact and recruit students in a way that is targeted and meaningful. Social media management tools like Hoot Suite or Social Bro offer the user the ability to monitor student-generated content through live streams of information. For example, a stream for one's college could be created, alerting a counselor when an individual types in pre-identified key words such as the college's name along with words like "stress" or "mental." This feed could track complaints, requests for assistance, questions, and comments, allowing counselors the opportunity to respond in real time with targeted answers and links to resources. A center could also follow its own Twitter followers and gain additional insight through students' tweets. This valuable information on how students communicate and what is currently trending could inform outreach, programming decisions and blogs, and provide a forum to interact with the community.

Social media is already being used to varying degrees by counseling centers and the mental health profession at-large. Online tools have been used to provide screenings and psycho-education for Major Depressive Disorder [9] and many counseling centers have resources and helpful links on their websites. Tapping into the capabilities of this media can allow counselors to be present, listen and offer guidance in innovative ways. As online courses have taken the professors out of the classroom and into students' homes, tweets, forums and graphics can bring some degree of a counseling presence to students around the clock. Tweets and other types of posts can be scheduled to be sent when counselors are out of the office, for example, sending links about dealing with stress along with stress management tips during finals week. Simply being present and reminding students that counselors are here raises the profile of the counseling center.

We are seeing more real-time mental health issues play out publicly

*Corresponding author: Corey $\mathrm{H}$ Basch, Department of Public Health, William Paterson University, USA, Tel: 973-720-2603; E-mail: BASCHC@wpunj.edu

Received December 13, 2013; Accepted December 23, 2013; Published December 24, 2013

Citation: Seidel EJ, Ethan D, Basch CH (2013) Using Social Media to Connect College Students with Mental Health Services. J Mass Communicat Journalism 4: e150. doi:10.4172/2165-7912.1000e150

Copyright: $\odot 2013$ Seidel EJ, et al. This is an open-access article distributed unde the terms of the Creative Commons Attribution License, which permits unrestricted use, distribution, and reproduction in any medium, provided the original author and source are credited. 
Citation: Seidel EJ, Ethan D, Basch CH (2013) Using Social Media to Connect College Students with Mental Health Services. J Mass Communicat Journalism 4: e150. doi:10.4172/2165-7912.1000e150

Page 2 of 2

as with the tweeted suicide of hip-hop artist Freddy E in early 2013 [10]. Researchers have begun to codify and track suicide-related tweets on Twitter, showing the possibility of real-time monitoring of individuals who are at risk for suicide [11]. Centers could have designated professionals monitoring and interacting with their social media on a regular basis. In some respects, this technology can act as an additional "counselor" on staff, with eyes and ears in places we haven't yet fully penetrated. We can agree that an online presence will never be a substitute for in-person professional interventions, and of course counseling centers need policies regarding use of social media including what is considered ethical and how it will be utilized [12]. Counselors would need to ensure and maintain student confidentiality and be mindful of their duty to protect privileged information even when operating in a virtual space where privacy can be minimal.

While there are certainly liability and confidentiality issues to address, counseling centers can expand their footprint and develop new ways for mental health professionals to reach out to students and become part of their online community. Counseling centers already work to develop outreach programs on campus, hoping to reach students who do not know about their services or have not sought out needed assistance. With the prevalence and severity of mental health issues rising on college campuses, we cannot let students fall through the cracks. Schools have an obligation to utilize every resource to reach out to students and meet their mental health needs for the good of the student, college, and community.

\section{References}

1. http://www.collegecounseling.org/wp-content/uploads/Survey-2013clinicians-3.pdf

2. http://www.acha-ncha.org/docs/ACHA-NCHA-II_ReferenceGroup_ExecutiveSummary Spring2013.pdf

3. Vogel DL, Wade NC, Hackler AH (2008) Emotional expression and the decision to seek therapy: The mediating roles of the anticipated benefits and risks. Journal of Social and Clinical Psychology 27: 254-278.

4. Ethan D, Seidel EJ (2013) On the front lines of student crisis: Urban community college professors' experiences and perceived role in handling students in distress. College Student Affairs Journal 31: 15-26.

5. Owen J, Rodolfa E (2009) Prevention through connection: Creating a campus climate of care. Planning for Higher Education 37: 26-33.

6. http://www.pewinternet.org/Reports/2013/Social-media-users.aspx

7. http://www.pewinternet.org/Reports/2012/Social-networking-climate/ Summary-of-findings.aspx

8. Moreno MA, Jelenchick LA, Egan KG, Cox E, Young H (2011) Feeling bad on Facebook: Depression disclosures by college students on social networking site. Depression and Anxiety 28: 447-455.

9. Youn SJ, Trinh N, Shyu I (2013) Using online social media, Facebook, in screening for major depressive disorder among college students. International Journal of Clinical and Health Psychology 13: 74-80.

10. http://www.mtv.com/news/articles/1699754/freddy-e-dead.jhtml

11. Jashinsky J, Burton SH, Hanson CL, West J, Giraud-Carrier C, et al. (2013) Tracking Suicide Risk Factors through Twitter in the US. Crisis: The Journal of Crisis Intervention and Suicide Prevention: Advance online publication.

12. Jenkins-Guarnieri M, Wright SL, Johnson B (2013) Development and validation of a social media use ntegration scale. Psychology of Popular Media Culture 2: 38-50. 